
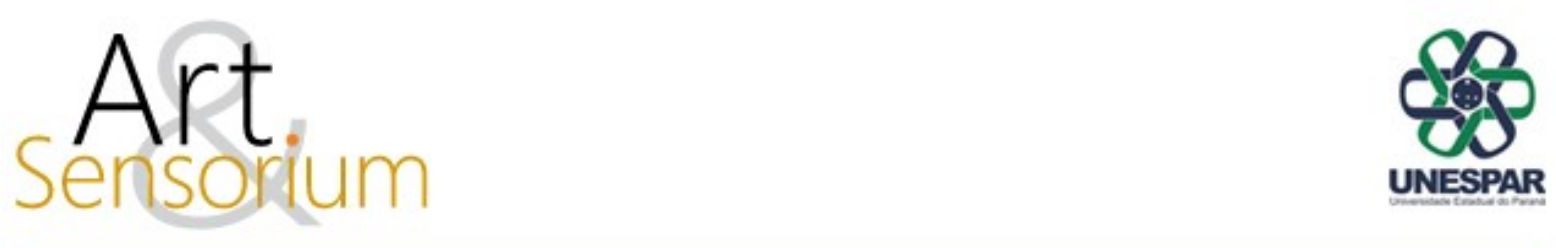

\title{
ASCENDENTES: PERDAS, RASTROS E RESTOS DAS TRAMAS HISTÓRICAS
}

\author{
https://doi.org/10.33871/23580437.2021.8.1.282-295
}

\section{Khetllen da Costa Tavares ${ }^{1}$}

\begin{abstract}
Resumo: Por meio desta poética visual discuto o processo de criação do livro de artista que elaborei intitulado Ascendentes (2020/21), gerado a partir das inquietações acerca do apagamento de mulheres afrodescendentes e indígenas nos arquivos históricos. O projeto poético integra minha pesquisa de doutorado na linha de processos artísticos contemporâneos, na qual investigo minhas raízes afroindígenas por meio de retratos fotográficos, com os quais construo livros de artista. Na ausência de fotos de minhas ancestrais, busquei no acervo do Museu da Imagem e do Som do Amazonas (MISAM), os rostos para preencher as lacunas do meu imaginário. Por meio do bordado reconstruo a minha memória familiar com representações de mulheres anonimadas desse museu. Tenho como referências teóricas discussões feministas decoloniais para destramar os fios dessa conturbada história.
\end{abstract}

Palavras-chave: mulheres afrodescendentes; mulheres indígenas; fotografia; livro de artista.

\section{ASCENDENTS: LOSSES, TRACES AND REMAINS OF HISTORICAL PLOTS}

Abstract: Through this visual poetics, I discuss the creative process of the artist book entitled Ascendents (2020/21). The book was created by me, it was generated from the concerns about the erasure of Afro-descendant and indigenous women in the historical archives. The poetic project integrates my doctoral research, in line with contemporary artistic processes, in which I investigate my Afro-indigenous roots through photographic portraits used in the construction of artist's books. In the absence of my ancestors' photos, I searched in the Museum of Image and Sound of Amazonas (MISAM) archive collection, for faces to fill in the gaps in my imagination. Through embroidery, I reconstruct my family memory with representations of anonymous women from this museum. I have as theoretical references decolonial feminist resareach discussions, to unravel the threads of this troubled history.

Keywords: African descent women; indigenous women; photography; artist book.

\section{ASCENDIENTES: PÉRDIDAS, RASTROS Y RESTOS DE TRAMAS HISTÓRICAS}

Resumen: A través de esta poética visual hablo del proceso de creación del libro de artista que elaboré, intitulado Ascendientes (2020/21), generado a partir de preocupaciones sobre la invisibilización de mujeres afrodescendientes e indígenas en archivos históricos. El proyecto poético integra mi investigación doctoral en la línea de los procesos artísticos contemporáneos en el que investigo mis raíces afro-indígenas a través de retratos fotográficos, con los que construyo libros de artista. En la ausencia de fotos de mis antepasadas, busqué en la colección del Museo de Imagen y

\footnotetext{
${ }^{1}$ Universidade do Estado de Santa Catarina (UDESC), Florianópolis (SC) Brasil, https://orcid.org/0000-0003-12349595. khetllencosta@hotmail.com
} 
Sonido de Amazonas (MISAM), los rostros para llenar las brechas/ espacios vacíos de mi imaginario. A través del bordado reconstruyo mi memoria familiar con representaciones de mujeres identificadas como anónimas de este museo. Tengo como referencias teóricas las discusiones feministas decoloniales para desenredar los hilos de esta historia conturbada.

Palabras-clave: mujeres afrodescendientes; mujeres indígenas; fotografía; libro de artista

\section{Introdução}

Por meio dos rastros e dos restos nas tramas dos retratos fotográficos, apresento Ascendentes (202021), a quarta obra (fig.1) que compõe a coleção de livros de artista que desenvolvo na pesquisa de doutoramento acerca da minha memória afro-indígena. No centro das investigações está a representação de mulheres africanas, indígenas e afro-indígenas que selecionei de acervos pessoais (álbuns de família) e públicos, entre eles, o Museu da Imagem e do Som do Amazonas (MISAM), no qual elegi fotografias realizadas entre a segunda metade do século XIX até a primeira do século XX.

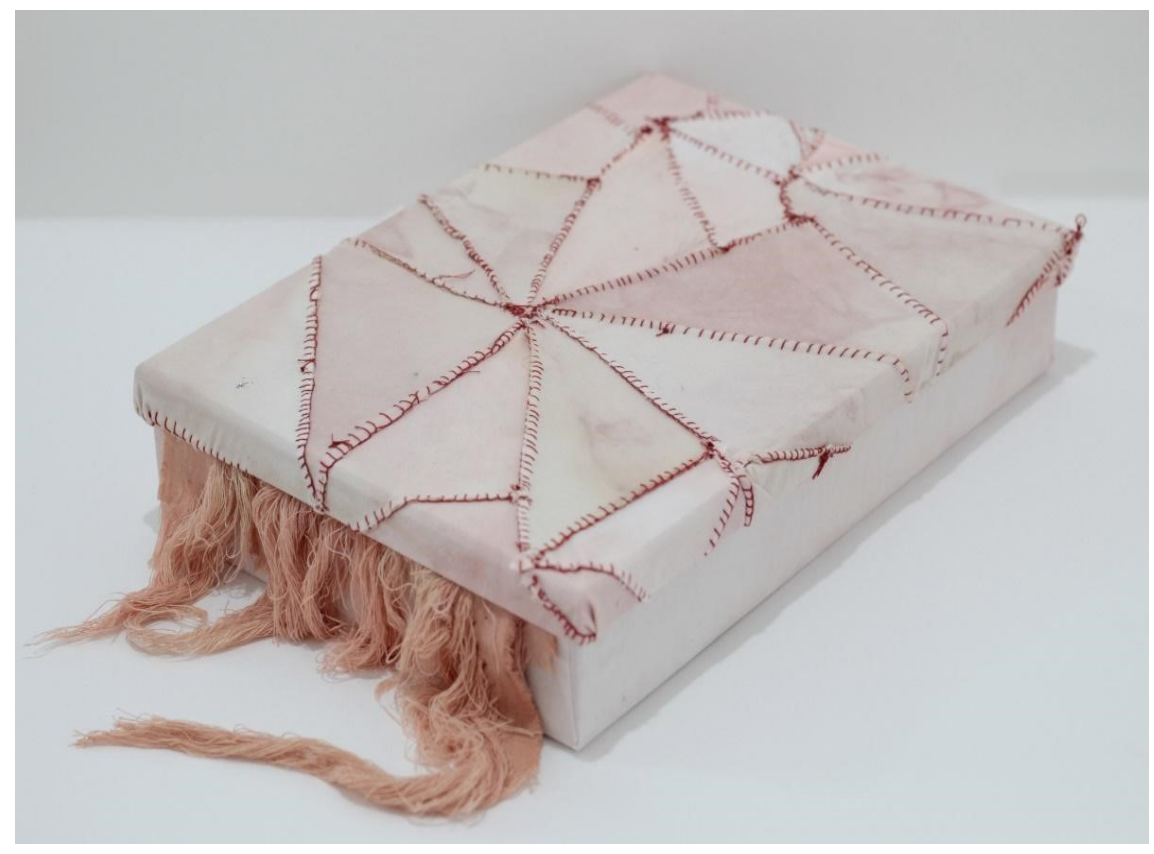

Figura 1. Ascendentes, $30 \times 21 \times 5 \mathrm{~cm}$. fototransferência sob tecido de algodão. 2020-21. Fonte: Acervo da autora.

Parte das inquietações iniciou com minha mudança de Manaus, cidade em que nasci, para estudar em Florianópolis no ano de 2018, três meses depois do falecimento da minha avó materna Norma Teixeira, a única ancestral com quem convivi. Nesse processo de deslocamento, vivenciei os contrastes raciais e culturais que afloraram questões em torno da minha identidade, ou seja, de como percebia minha etnicidade afro-indígena, característica que permaneceu por muitos anos nebulosa para mim. Em Florianópolis, por vezes, as pessoas me perguntavam de qual país da América Latina eu procedia e, em algumas ocasiões, até falavam comigo em espanhol por achar que era estrangeira. Quando perguntava o motivo do questionamento, me diziam que era pelos meus traços fisionômicos indígenas. O curioso desse tratamento é que ter traços afro-indígenas na região Sul parece significar não ser brasileira. 
Ao pesquisar outras artistas que se reconectaram com sua ancestralidade a partir da diáspora, conheci a biografia da artista afrodescendente Marcela Bonfim ${ }^{2}$, cuja identidade ancestral floresceu depois que se mudou de São Paulo, seu lugar de nascimento, para Rondônia em 2010, onde foi apontada pela população local como barbardiana, isto é, descendente de famílias afro-caribenhas que migraram para a região amazônica no período da construção da Estrada de Ferro Madeira-Mamoré, entre 1907 e 1912. Sobre o processo de nomeação, a artista declarou: "Aqui, meu corpo é político. E meu primeiro clique, quem deu, foi Rondônia. Foi como se o Estado tivesse me falado, depois de tudo o que eu tinha enfrentado em São Paulo: 'Olha aqui, garota: levanta a cabeça igual Barbadiana'" (BONFIM apud CARVALHO, 2020). Atualmente, Bonfim representa os fluxos migratórios negros e o fortalecimento da negritude por meio do projeto fotográfico (Re)conhecendo a Amazônia Negra: povos, costumes e influências negras na floresta, que expôs pela primeira vez, no ano de 2016, no Espaço Cultural Cujuba, na cidade de Porto Velho (Rondônia). (CARVALHO, 2020).

Moara Tupinambá, ${ }^{3}$ natural de Belém (Pará), residente em São Paulo desde 2010, artista que reflexiona sobre sua ancestralidade por meio da poética, comentou os racismos que vivenciou após sua mudança de cidade: "Me questionaram se eu era índia mesmo, [...] já me falaram para retirar o meu brinco de pena, 'pois não precisava reforçar dentro de um escritório a minha 'cara de índia"" (BRASIL, 2019). Tais ações apontam para os silenciamentos das identidades indígenas em espaços institucionalizados. Moara pesquisa o apagamento e resistência da memória indígena por meio da sua genealogia familiar, com intuito de revelar as consequências dos processos de colonização no contemporâneo. Em Museu Silva, a artista indígena organizou um possível museu dedicado à própria família paterna, que é do povo de Cucurunã (comunidade rural próxima à cidade de Santarém) e de Boim (comunidade dos Tupinambaranas). Por meio de fotografias, mapas, documentos, entrevistas com familiares e amigos de seus genitores, apresenta a memória de seus parentes que atravessa o próprio território. O projeto integrou a exposição A Mostra de Arte Terra Indígena Digital, no Espaço Cultural Colabirinto, na cidade de São Paulo, em agosto de 2019 (REDE CHOQUE, 2020).

Retornando a minha história, procuro a ancestralidade na biografia de mulheres que geraram meu núcleo familiar. Comecei pelos álbuns de família, que logo revelaram a ausência de imagens dessas ancestrais, o que me conduziu ao MISAM com propósito de autorreconhecimento. Prossegui com a pesquisa nessa instituição e percebi que o número de retratos de mulheres afrodescendentes era menor, comparados ao de indígenas. Além disso, no inventário do museu, observei a falta dos nomes das fotografadas nas legendas, nos quais constava apenas uma descrição da cena ou a indicação "mulher não identificada".

Para compreender os possíveis motivos que levaram ao apagamento das retratadas em estudo, primeiro procurei a teoria da fotografia em torno do período oitocentista, no qual os eugenistas

\footnotetext{
${ }^{2}$ Marcela Bonfim (1983) nasceu em Jaú, interior de São Paulo. Atua em Porto Velho, Rondônia, onde vive em uma comunidade à beira do rio Madeira. Bonfim é formada em Ciências Econômicas (2008) pela Pontifícia Universidade Católica de São Paulo (PUC-SP). É especialista em Direitos Humanos e Segurança Pública pela Fundação Universidade Federal de Rondônia (UNIR - 2011). A poética da artista fundamenta-se na constituição e memória da população afrodescendente na região amazônica, sendo desenvolvida no campo da fotografia e da produção audiovisual, por meio de trabalhos autorais e colaborações com algumas instituições e órgãos, a exemplo do Instituto Chico Mendes para a Biodiversidade (ICMBio - 2015) (BONFIM, 2016).

${ }^{3}$ Moara Tupinambá Brasil (1983-) é artista visual e curadora ativista, atuou nos setores de criação de moda e ilustração até dedicar-se à produção artística. Radicada em São Paulo, a artista é multiplataforma, pois desenvolve trabalhos em diversas técnicas, como desenho, pintura, colagens, instalação, fotografia, performance, mas também em literatura. Integra os coletivos Colabirinto e Mulheres Artistas Paraenses (MAR). Participa de eventos nacionais e internacionais, dentre os quais se destacam: Bienal de Sydney, 2020 (curador Brook Andrew) com a produção do vídeo inédito da Marcha das Mulheres Indígenas (2019); indicação ao Prêmio de Arte e Educação da Revista Select (2018), pelo projeto II Bienal do Ouvidor 63, ocorrido na maior ocupação artística de São Paulo, e Seminário de Histórias Indígenas do Museu de Arte de São Paulo, quando expôs o projeto Museu da Silva (2020) (BRASIL, 2020).
} 
utilizaram a câmera para legitimar seus discursos que, como já bem conhecidos, visavam ao "aperfeiçoamento" da espécie humana. Para tanto, produziram coleções fotográficas dedicadas à racialização dos corpos negros e indígenas. A partir de então, reflito a respeito da invisibilidade dessa população nos acervos fotográficos na capital amazonense e também sobre a forma como as mulheres foram fotografadas e catalogadas nos inventários do museu.

Mediante os questionamentos apresentados, neste texto exponho a elaboração do livro de artista Ascendentes (2020-21), no qual trago manualidade oriunda do cotidiano do lar onde cresci, como o bordado e a costura. Articulo as investigações poéticas com os estudos acerca do apagamento de mulheres em arquivos públicos; para tanto, recorri aos escritos de outras pesquisadoras e artistas contemporâneas, especialmente aquelas de teorias feministas decoloniais ${ }^{4}$, que me auxiliam a destramar e tramar as páginas de Ascendentes, entre elas: Luana Tvardovskas, Lélia Gonzalez, e trabalhos poéticos de Marcela Bonfim, Moara Brasil e Cecilia Vicuña. Além disso, relato aspectos processuais do livro e as reflexões geradas com sua produção.

\section{Ascendentes}

Nos debates feministas contemporâneos nas artes visuais, é notório o apagamento de mulheres artistas na história da arte canônica. Ao longo dos séculos e atualmente, entendi que o apagar da historiografia é ainda maior para as mulheres negras e indígenas. Por exemplo, os estudos de pesquisadoras como Linda Nochlin (1971), nos Estados Unidos, e Ana Paula Simioni (2007), no Brasil, evidenciaram os problemas no sistema das artes que influenciaram esses desaparecimentos. Entre os diferentes fatores que as artistas enfrentavam, podemos citar os impedimentos familiares, a dificuldade de acesso às instituições de ensino formal e humilhações relacionadas ao gênero, à classe e - muito em especial à raça. Em alguns casos, havia crítica especializada acerca da produção; porém, foi na escrita da história da arte realizada no período moderno que ocorreu a supressão das narrativas a respeito dessas mulheres (NOCHLIN, 2016; SIMIONI, 2007).

$\mathrm{O}$ apagamento de mulheres nos acervos de artes visuais me afetou enquanto mulher artista, levandome a adotar uma atitude de enfrentamento e denúncia frente a essa exclusão que se revela em outros acervos de memória cultural, a exemplo dos arquivos que encontrei no MISAM. O ato de excluir mulheres afrodescendentes e indígenas me atravessa, e por isso me sinto convocada a atuar nas lacunas em torno das biografias das retratadas do acervo pesquisado, com a proposição de como representar essa exclusão por meio de um livro de artista: operar nas ausências a partir da autobiografia.

A autora feminista Lélia Gonzalez, quando propôs um feminismo afro-latino-americano, apontou as profundas desigualdades raciais existentes em nosso continente. No sistema capitalista patriarcalracista, a discriminação contra mulheres não brancas é ainda maior; logo, são as mais oprimidas e exploradas. Para Gonzalez (1988, p. 17), “[...] este sistema transforma as diferenças em desigualdades, a discriminação que elas sofrem assume um caráter triplo; dada sua posição de classe, ameríndias e amefricanas fazem parte, na sua grande maioria, do proletariado afrolatinoamericano[...]”. Tal processo evidencia a articulação entre gênero, raça e classe. Além disso, nega o direito à voz, não apenas na forma do discurso, mas também na construção da própria história (GONZALEZ, 1988).

Envolvida nessas questões, me deparei com a impossibilidade de encontrar as identificações das fotografadas no MISAM, o que me levou à busca pela nomeação de minhas ancestrais, que encontrei nas lembranças da mamãe Suame da Costa e das tias Suely Marreiros e Maria Lúcia Ribeiro. Os

\footnotetext{
${ }^{4} \mathrm{O}$ termo decolonial é adotado nesta pesquisa de acordo com a perspectiva da pesquisadora da Universidade Andina Simón Bolívar (Equador) Catherine Walsh, que considera o "des" como ideia de desmontar, reverter ou desfazer, isto é, adentrar em um momento não colonial; sendo assim, a autora reflexiona acerca dos padrões e consequências do colonialismo que não podem ser apagados (WALSH apud ADAMS, 2015).
} 
documentos oficiais não dão conta dessas existências; houve perdas de certidões de nascimento e óbito, bem como de carteiras de identidade, que nem sempre foram adquiridas. Do lado materno, ainda há fragmentos de alguns desses registros, mas na família paterna os rastros deles estão nas entrelinhas, pois são oriundos de Nhamundá, interior do Amazonas, lugar de difícil acesso aos cartórios. Por exemplo, na primeira metade do século XX, período em que meus familiares viveram, o estabelecimento mais próximo estava localizado em Faro, município paraense que é fronteiriço com o Amazonas. A despeito das dificuldades, continuo a procurar por essas mulheres cujos vestígios, de algum modo, trago em mim.

Traduzo esses caminhos poeticamente no bordado dos nomes e sobrenomes de minhas parentes nas páginas de tecido (fig.2) que compõem o livro de artista Ascendentes (2020-21). Utilizo a mesma escrita capaz de apagar para homenagear aquelas anonimizadas nos acervos públicos e me lembrar daquelas com quem não convivi, como as bisavós e as tataravós.

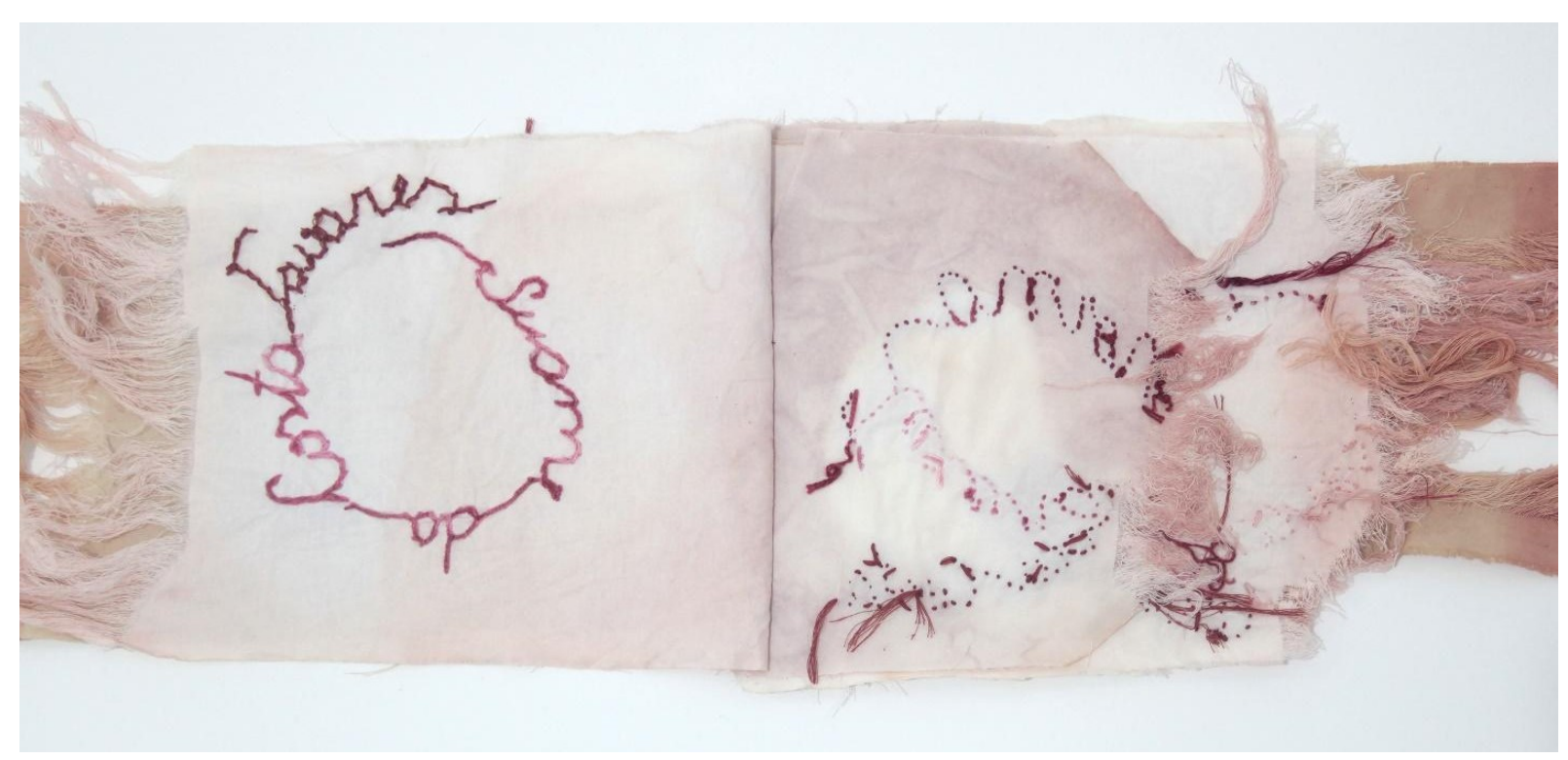

Figura 2. Ascendentes, $30 \times 21 \times 5 \mathrm{~cm}$. Fototransferência sob tecido de algodão. 2020-21. Fonte: Acervo da autora.

Compreender minha ancestralidade por meio do feminino relaciona-se com a trajetória do meu núcleo familiar, fundamentado na figura das matriarcas. Minha avó materna, Norma Teixeira da Costa, nasceu em Manaus no ano de 1937, onde permaneceu até sua morte em 2018. Perdeu seu pai, José Teixeira, quando ainda era criança. Com as dificuldades financeiras que essa perda gerou, sua mãe Maria Nazaré Teixeira não pôde arcar com as despesas da escola dos filhos; assim, vovó não continuou com os estudos depois do primário. Casou-se pela primeira vez aos dezesseis anos com o senhor Ferreira e teve um casal de filhos. Depois da separação, começou a lavar roupa para fora com o intuito de garantir o sustento das crianças. Adiante, minha avó uniu-se em matrimônio com vovô Ambrósio Rodrigues da Costa, com quem gerou seis filhos: duas meninas e quatro meninos. Após o segundo divórcio, tornou-se a matriarca da família. Mesmo diante dos desafios, vovó sempre manteve a família que formou.

Minha mãe, Suame da Costa Tavares, é uma mulher afrodescendente manauara. Nasceu em 1965 e começou a trabalhar cedo como professora da educação infantil para ajudar na renda familiar. Aos dezoito anos, ingressou na Polícia Militar do Estado do Amazonas - PMAM. Foi a única fillha que seguiu a carreira profissional de seu pai, o senhor Ambrósio da Costa, que serviu por trinta anos na PMAM. Em 1989, casou-se com Jose Lucio Ribeiro Tavares, meu pai, com quem compartilha sua vida desde então. Em 1983, mamãe voltou a ministrar aulas e completou dez anos como docente. 
Retornou à polícia em 1993, onde permaneceu até se aposentar em 2005. Nessa ocasião, voltou aos estudos formais e graduou-se em direito em 2011.

As biografias da vovó Norma e da mamãe Suame me levaram desde a infância a olhar com naturalidade a centralidade da mulher na família. Também despertaram em mim o interesse pelo livro e pela costura. O primeiro veio da mamãe, que colecionava muitas publicações, as quais formavam empilhamentos pelos cômodos da casa, enquanto a segunda aprendi com vovó Norma, que costurava as roupas dos filhos e, mais tarde, dos netos. Por isso, tais elementos perpassam a elaboração do livro de artista apresentado (fig. 3).

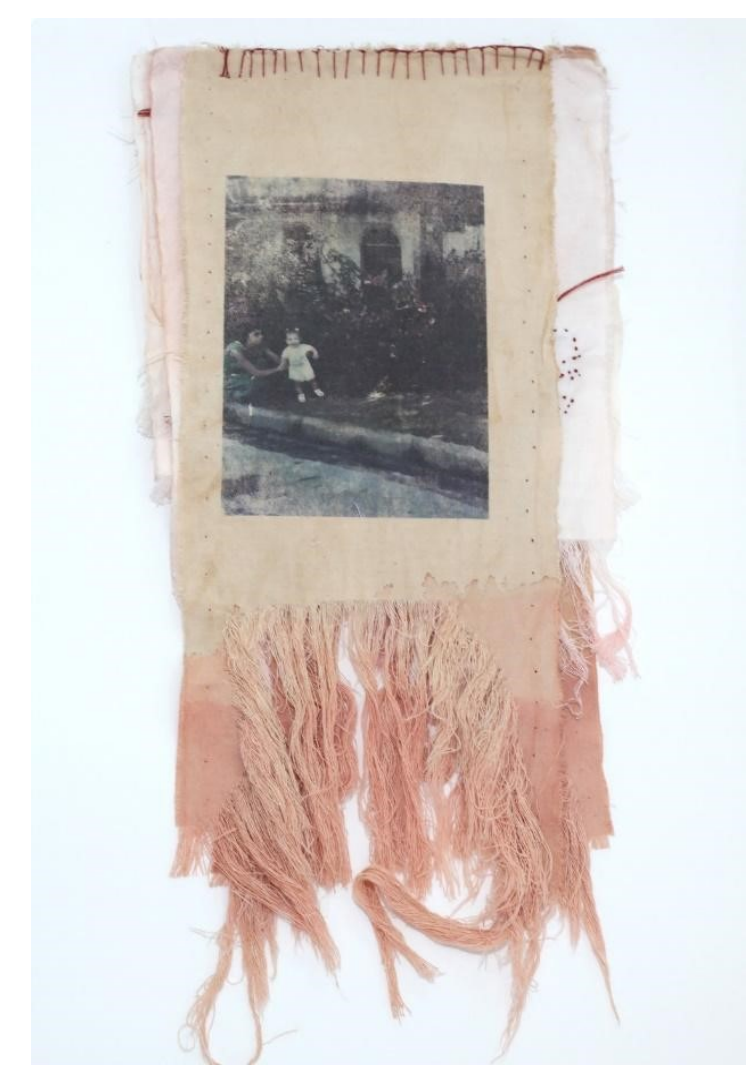

Figura 3. Ascendentes, $30 \times 21 \times 5 \mathrm{~cm}$. Fototransferência sob tecido de algodão. 2020-21. Fonte: TAVARES, Lucio. Vovó Norma Teixeira, 1991, Manaus. Acervo da família Teixeira Costa Tavares.

A obra Ascendentes é composta por uma caixa envelopada com tecido (fig.4), material que tece nossas vidas, a tessitura de uma história compartilhada entre vovó, mamãe e eu. A tampa é forrada por pedaços triangulares de pano unidos pela costura, que aludem à forma do alicerce familiar a que pertenço, composto por três mulheres que se conectam por linhas de afetos ao longo de gerações, como o tempo de um caseado elaborado manualmente. Além disso, a colcha de retalhos remete às tramas de segredos que compartilhávamos durante as rodas de conversa na cozinha da casa da matriarca, onde desfrutávamos das histórias que ela nos contava acerca de suas vivências com outras mulheres, com as quais partilhava receitas, remédios e conselhos. A agulha marca, o ponto traça, o caseado une. Na costura, os fios formam caminhos que se encontram como a história da minha família, que pode se entrelaçar à de tantas outras. 


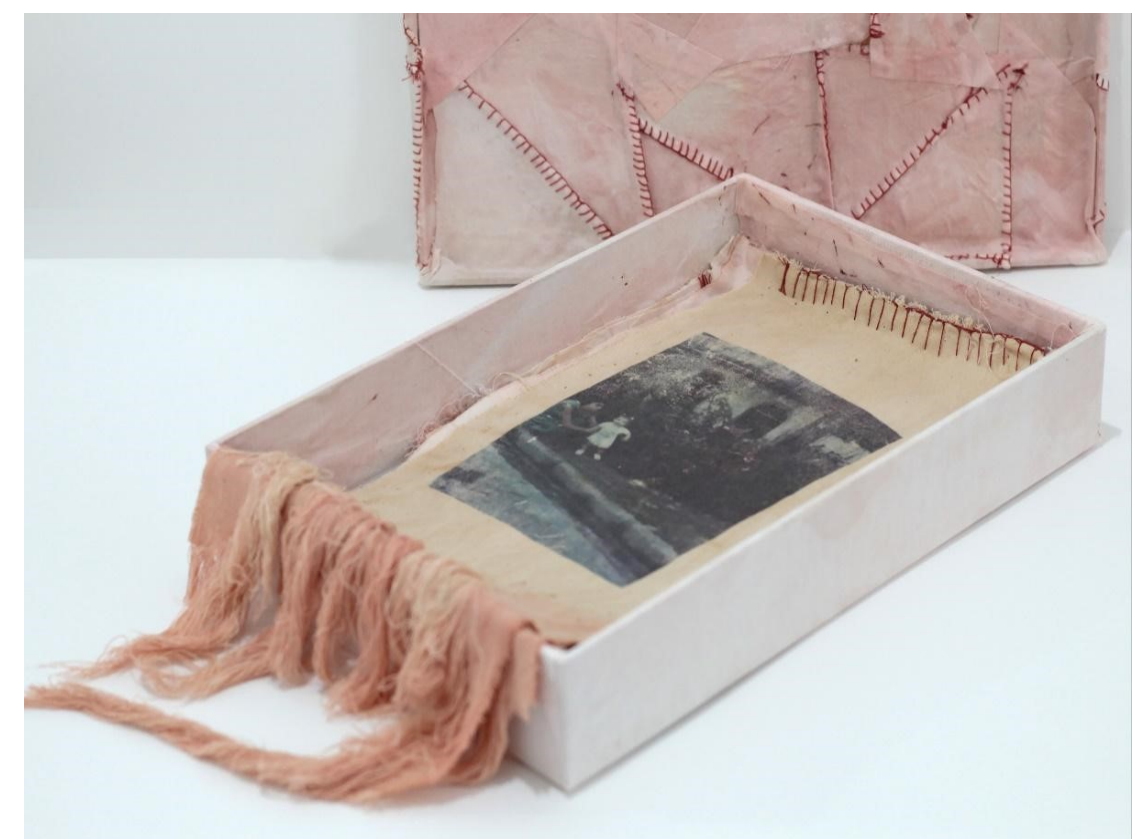

Figura 4. Ascendentes, $30 \times 21 \times 5 \mathrm{~cm}$. Fototransferência sob tecido de algodão. 2020-21. Fonte: Acervo da autora.

No interior da caixa estão nove páginas de tecido com as bordas inferiores desfiadas (fig. 5). Apresento nelas os bordados dos nomes das parentes na seguinte ordem: mamãe, avós, bisavós e uma tataravó materna. Existem, na frente das páginas, pontos e fios soltos que parecem desconexos, mas que, quando viradas, possibilitam a leitura dos nomes das mulheres. O desfazer das tramas permite que se veja parte da escrita da página anterior ao folhear o livro. Há duas fotografias: a primeira é uma cena de vovó Norma me apoiando quando bebê, e a segunda mostra uma mulher afrodescendente em uma varanda com um bebê nos braços e outra criança próxima a ela, registro vindo do acervo do MISAM. Ambas foram impressas por meio do procedimento de fototransferência, no qual a imagem sofre a corrosão que evidencia o aspecto de perda, rastro e resto que elegi como conceitos centrais no processo de criação da coleção de livros.

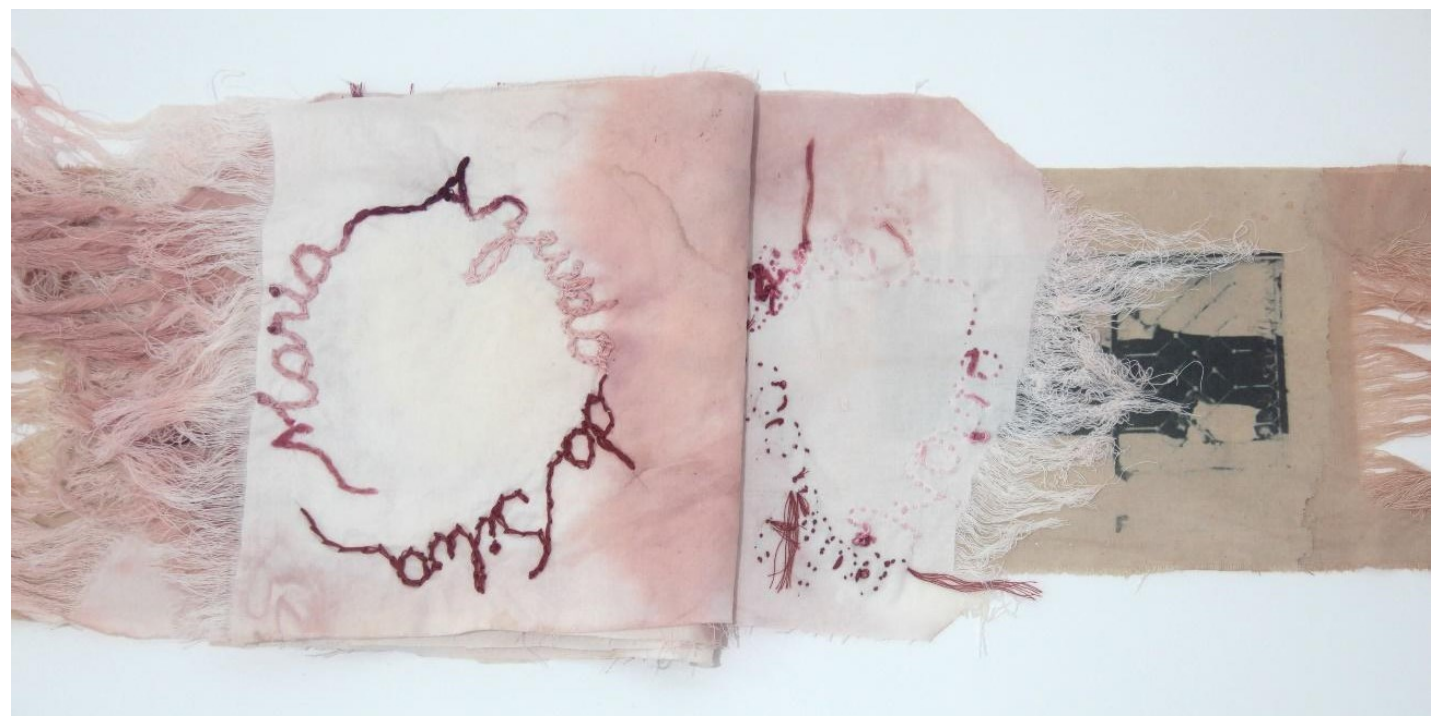

Figura 5. Ascendentes, $30 \times 21 \times 5 \mathrm{~cm}$. Fototransferência sob tecido de algodão. 2020-21. Fonte: Acervo da autora. 
Começo a narrativa do livro com a fotografia da minha avó Norma. Ela é a ponta da trama que desatei para encontrar as outras mulheres que me formaram. Como mencionei anteriormente, vovó compartilhou comigo as lições de costura; às vezes comentava que eu era a única de suas descendentes que manifestava esse interesse. Na prática desses saberes que são transmitidos de geração a geração entre mulheres, a autora norte-americana Alice Walker comentou que "nossas mães e avós, quase sempre anonimamente, nos têm provido centelhas criativas, a semente de uma flor que elas mesmas nunca esperam ver: ou como uma carta selada que elas não podiam ler plenamente" (WALKER, 1972, p. 5). Assim, todas as histórias que escrevemos são de nossas ancestrais, não apenas pelo conteúdo em si, mas pela forma como esse discurso é materializado.

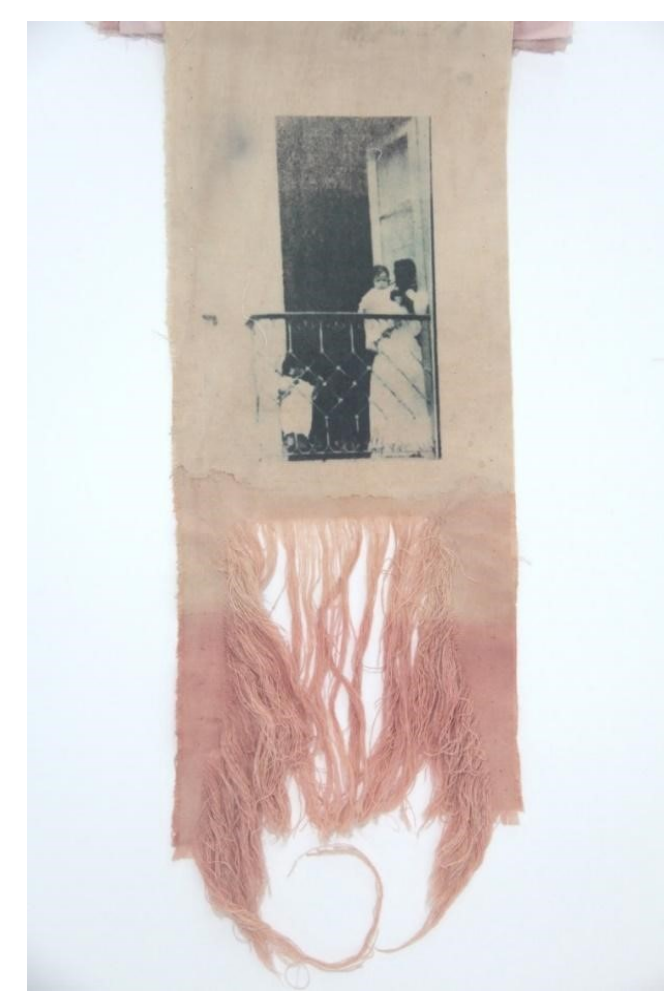

Figura 6. COSTA, Khetllen. Ascendentes, $30 \times 21 \times 5 \mathrm{~cm}$. Fototransferência sob tecido de algodão. 2020-21. Fonte: Museu da Imagem e do Som do Amazonas. Autor: George Hubner, Anuário de Manaus de 1913-1914. Dimensão: 21 $\mathrm{cm} \times 14,3 \mathrm{~cm}$.

Finalizo o livro com a imagem da retratada segurando um bebê nos braços (fig. 6), pois a associo com minhas avós, bisavós e tataravós, que nunca conheci. A ausência de fotos de minhas ancestrais me conecta afetivamente àquelas mulheres que acessei nos arquivos do museu, uma vez que os rostos delas preenchem meu imaginário. 

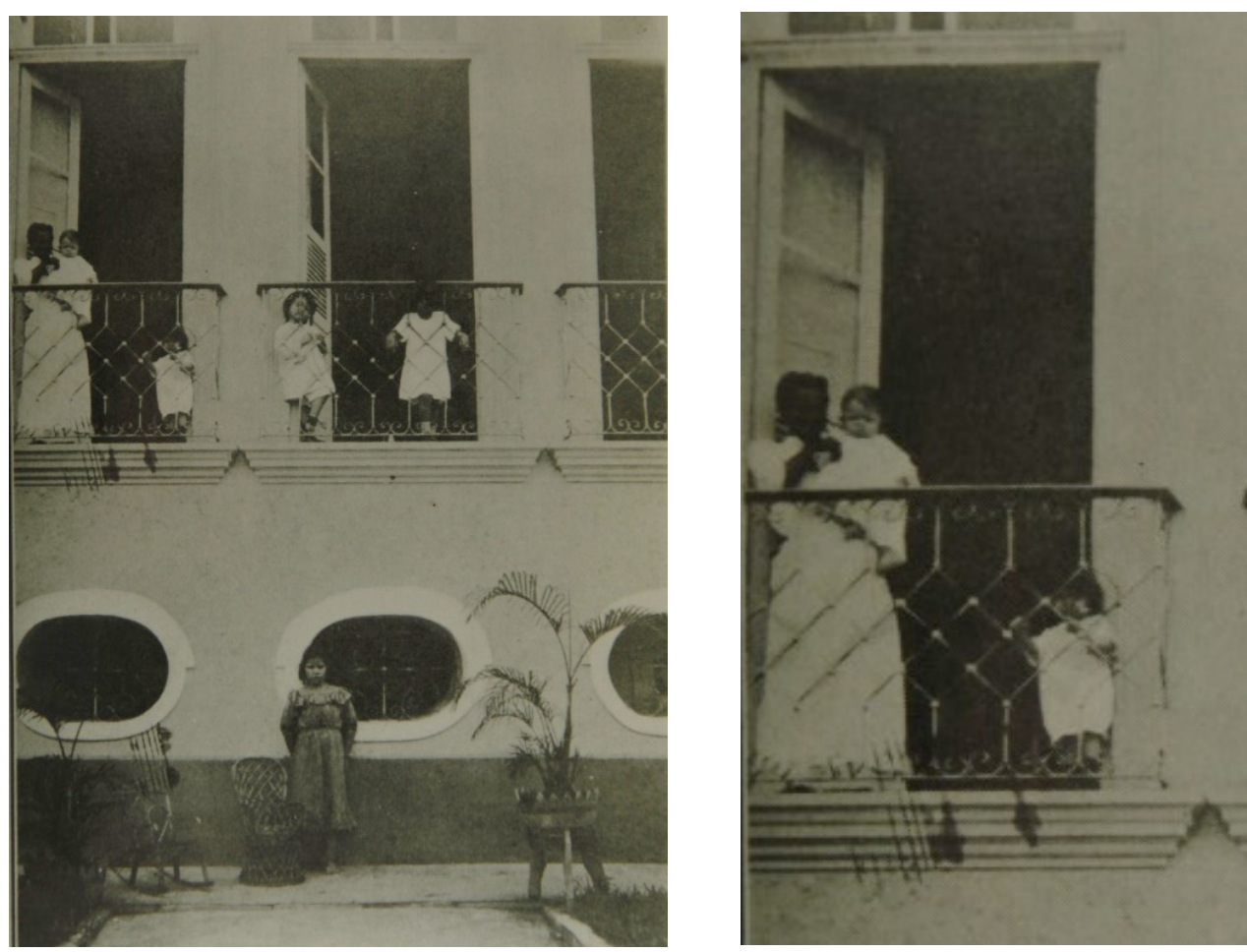

Figura 7. HUBNER, George. Anuário de Manaus de 1913-1914. Dimensão: $21 \mathrm{~cm} \times 14,3 \mathrm{~cm}$. Fonte: Museu da Imagem e do Som do Amazonas.

Para destacar a personagem da foto acima (fig. 7), realizei o corte observado no detalhe da figura sete. Posicionada no canto esquerdo da varanda, não conseguimos observar a fisionomia da retratada, o que aproxima sua representação de uma sombra. Trata-se, portanto, de uma presença que não se revela em sua totalidade, aspecto que se interliga com a forma como essa imagem foi catalogada no inventário do museu, identificada sob a descrição "Crianças na varanda de uma casa". "Mulher", "negra" ou outra indicação de sua etnia não consta no inventário. Encontrei essa imagem no exercício de olhar envelope por envelope e cheguei a acreditar que a foto não constava no relatório oficial. Depois de conferir a lista, observo que essa mulher foi invisibilizada no processo de catalogação.

Nessa relação entre a representação de mulheres afrodescendentes e a sombra (aquela que não é nominada), lembro Marcela Bonfim quando comenta que, embora a técnica fotográfica se baseie na escrita da luz, ela está interessada na sombra, pois o excesso de luz impossibilita a visão e pode apagar, enquanto a sombra leva à imaginação e permite enxergar imagens não reveladas (BONFIM, 2020a). Além disso, para a fotógrafa, "um corpo negro não fala por si só, aliás nunca falou, mas fala por tantos outros" (BONFIM, 2020b). Portanto, a retratada invisibilizada no inventário desvela o apagamento de uma parcela da população que não pode mais ser excluída das páginas oficiais. Por mais que a historiografia oculte tais mulheres nos acervos, elas se revelam nos rastros que apontam os restos de memória.

O modo técnico como a fotografia analisada foi elaborada parece aludir ao processo de apagamento em que a retratada estava confinada, o qual se expandiu para além do tempo cronológico e atravessou séculos. Embora essa mulher tenha sido invisibilizada nas narrativas oficiais, me conecto com ela, pois a cena me lembrou as tardes que passava com vovó Norma à beira da janela, olhando a rua de casa no período da minha infância. Além disso, essa imagem é uma possibilidade de acessar minhas ancestrais africanas e indígenas com quem não tive a oportunidade de conviver, mesmo que por fotografia. Olho para a fotografada com a lembrança da minha bisavó materna, Narcisa Rodrigues da Costa, que nunca pude conhecer. 
A feitura dessa obra se relaciona com a proposição de destramar a história da minha família e habitar a casa como ateliê no período da pandemia da covid-19, que impossibilitou temporariamente o uso dos laboratórios da universidade. Utilizo o procedimento de fototransferência ${ }^{5}$ para imprimir as imagens dos livros. Atualmente, minha experimentação foi interrompida pela falta de acesso à prensa de gravura. Escolhi trabalhar com imagens impressas que não constam no livro anterior. Desfiz o crochê nas bordas do tecido impresso com as fotos, e as marcas da agulha no pano permaneceram como a falta, o vazio, aquilo que foi retirado ao anonimato do passado/presente. A seguir, em outros tecidos, iniciei o bordado dos nomes de minhas ancestrais, que depois tingi, e os manchei para manter o conceito de perda.

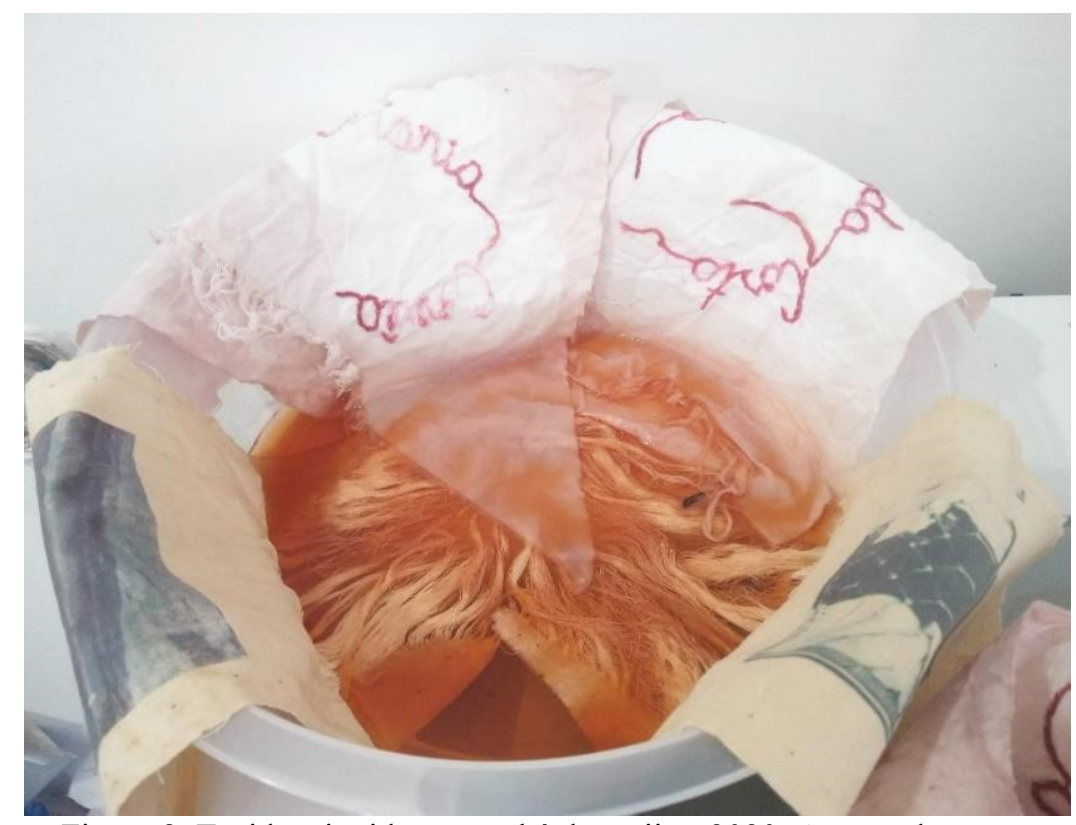

Figura 8. Tecidos tingidos com chá de crajiru. 2020. Acervo da autora

Vovó Norma cresceu no interior do Amazonas, em meio a culturas de mulheres indígenas e afrodescendentes que se utilizavam do chá de crajiru ${ }^{6}$ para tratar as enfermidades relacionadas ao útero e aos ovários. Lembro que ela preparava as garrafadas para todas as mulheres da família, principalmente em recuperação de algum pós-cirúrgico. Escolhi tingir os tecidos com a infusão dessa planta (fig. 8), pois representa o cuidado que minha avó tinha com todas as parentes, mas também evidencia a potência criativa dessas mulheres que vai além da fertilidade de seus corpos e atravessa seus saberes e práticas.

Para historiadora brasileira feminista Luana Tvardovskas, o uso recorrente de elementos autobiográficos na produção de mulheres artistas contemporâneas auxilia na problematização em torno de temáticas consideradas feministas como memória, casa e corpo. Nesse contexto, um objeto pode ser um vestígio da vivência individual que abala a memória oficial da história e da cultura (TVARDOVSKAS, 2017).

A partir disso, indaguei a escolha dos materiais e procedimentos que utilizei nesse livro: a caixa, o retalho, a costura e o bordado. Recordo o período da minha infância, quando abria a gaveta retangular

\footnotetext{
${ }^{5}$ Procedimento em que se transpõe uma imagem para outro suporte por meio do uso de solvente e ajuda da prensa de gravura. A solução química provoca uma corrosão que reduz a nitidez da foto, bem como, por vezes, esta não é transferida em sua totalidade, visto que o resultado varia de acordo com a potência da prensa sob o suporte.

${ }^{6} \mathrm{O}$ crajiru é uma planta nativa da Amazônia de porte arbustivo, muito utilizada devido às suas propriedades antiinflamatórias que combatem doenças inflamatórias e reumatológicas (MARTINS, 2017). Para auxiliar a saúde da mulher, o chá pode ser usado na higiene íntima ou ingerido.
} 
de madeira da máquina de costura da vovó Norma para ver o que ela guardava ali. Lembro que sempre encontrava retalhos que sobravam dos ajustes das roupas que ela fazia junto aos carretéis de linhas, que às vezes se cruzavam com os tecidos e formavam um emaranhado semelhante aos fios das lembranças que anovelam a memória da nossa própria história. Vejo esse livro como um segredo de família que compartilho com quem abre a caixa ao modo de uma criança curiosa que quer descobrir o que a avó guarda em uma gaveta.

Na montagem, optei por apresentar o avesso do bordado como frente da página, pois é no avesso da história que encontramos as mulheres ignoradas na cultura do Brasil. Se, de um lado, os versos dos pontos mostram os vazios, do outro, os versos da poética os preenchem. Ao folhear as páginas, os nomes das mulheres veladas são revelados. O curso cíclico representa a interconexão entre essas pessoas que atravessam temporalidades diferentes. O vazio entre os pontos (fig. 9) liga-se às ausências de imagens e documentos de identificação com que lidei ao longo dessa pesquisa, a exemplo dos fios e dos tecidos desbotados que remetem aos apagamentos sofridos, visto que histórias de mulheres afrodescendentes e indígenas foram invisibilizadas por séculos nos versos das narrativas oficiais.

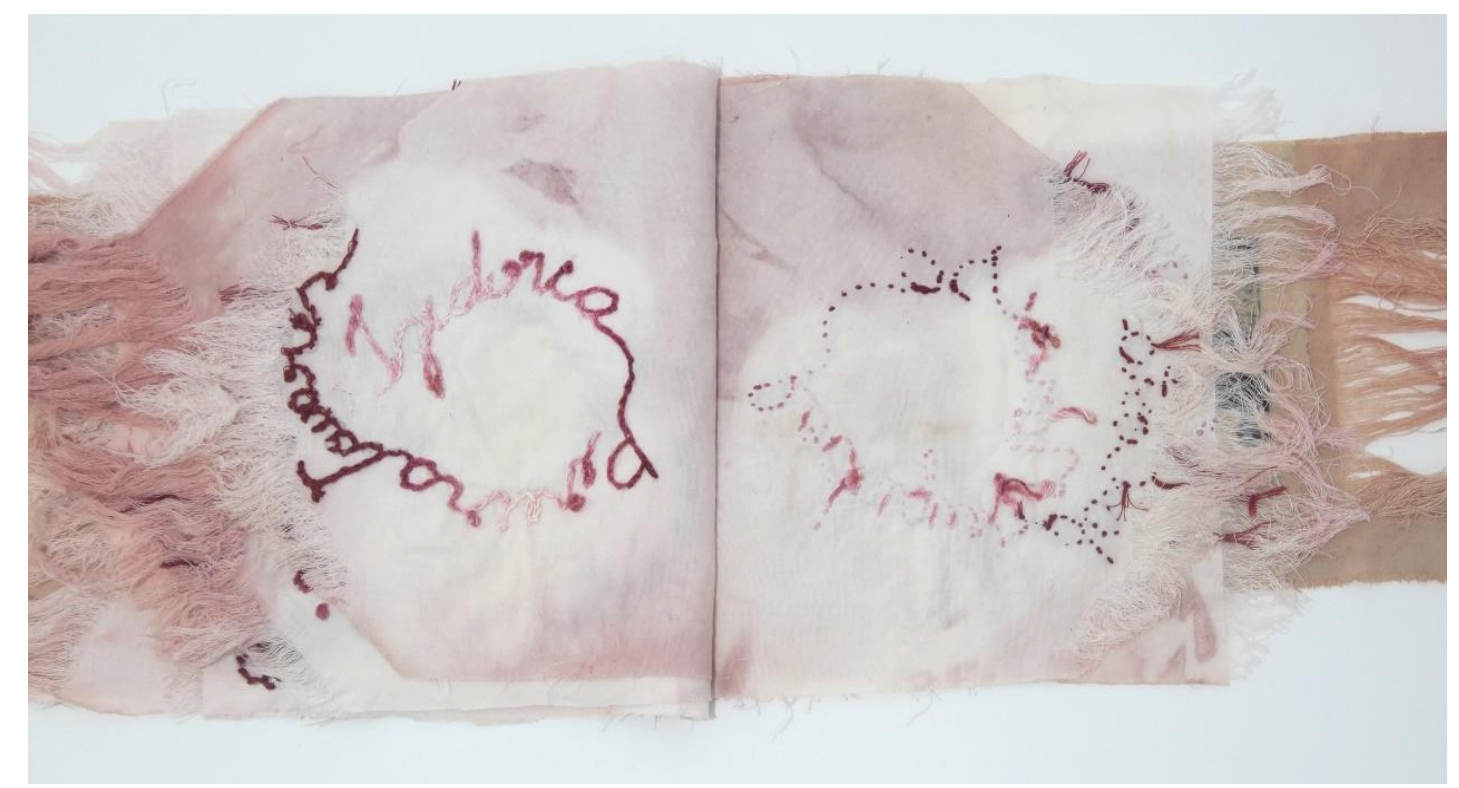

Figura 9. Ascendentes, $30 \times 21 \times 5 \mathrm{~cm}$. Fototransferência sob tecido de algodão. 2019-20. Fonte: Acervo da autora.

Encontrei acolhimento também nas reflexões poéticas da artista chilena Cecilia Vicuña, de ascendência indígena, que começou seu percurso artístico na pintura durante os anos 1960, mas exilou-se na Inglaterra e nos Estados Unidos em decorrência do golpe de 1973. A artista transita pelo território da mestiçagem em sua poética, além de habitar o entre-lugar ${ }^{7}$, pois estabelece a reconexão com suas identidades étnicas. Entre as principais articulações propostas por Vicuña, está a luta contra a homogeneização cultural junto à prática têxtil-textual referente às histórias silenciadas de mulheres indígenas (OLIVEIRA, 2019).

\footnotetext{
${ }^{7}$ Para Bhabha (1998, p. 221) o entre-lugar “contesta genealogias de 'origens' que levam a reivindicações de supremacia cultural e prioridade histórica. [...] não celebrarão a monumentalidade da memória historicista, a totalidade da sociedade ou a homogeneidade da experiência cultural". Assim, atuar nesse entre-lugar é priorizar as contranarrativas que põem em xeque a memória historicista, que rasuram as fronteiras ao focarem no lugar habitado pelas minorias, no qual o poder de fala destaca as identidades que foram invisibilizadas em processos totalizadores.
} 
No livro de artista La realidad es una línea (1994), formado por uma folha de papel sulfite dobrada na qual está escrita a frase que o nomeia, Vicuña relaciona a realidade com a linha, algo contínuo da supremacia cultural na prioridade da história. A artista afirma: "O meu trabalho vagueia pelo que ainda não aconteceu, pelo potencial futuro do que ainda não foi formado, onde som, tecelagem e linguagem interagem para criar novos significados." (VICUÑA apud OLIVEIRA, 2019, p. 2). Nessa proposta, ela tensiona a relação entre fio, linha, tessitura e palavra, característica relacionada com as camadas presentes no uso do têxtil nas culturas andinas, como comunicação, memória cultural, ritual, posicionamento político, entre outros (ZEGHER apud OLIVEIRA, 2019).

No entendimento da palavra como fio do tempo que compõe uma história, Vicuña utiliza a tessitura de acordo com os ensinamentos andinos em que a palavra para linguagem é fio e a conversa complexa o bordado. Tal visão se contrapõe à ocidental, que rotula o bordado e a tapeçaria como práticas menores dentro do fazer artístico, segregando-os da esfera das artes ditas como "maiores". Para Cecilia Vicuña, as mulheres latino-americanas indígenas sempre utilizaram o tecido como outra forma de discurso, pois o fio atravessa mundos e margens (OLIVEIRA, 2019). Ao trazer a tessitura para o trabalho poético, evocamos uma expressão feminista e decolonial.

A partir dessas questões lançadas pela artista chilena, penso poder dizer que, se a realidade para ela é uma linha, a realidade da minha família é um fio desbotado e esgarçado nas páginas oficiais. Me pergunto como construir novos significados por meio desses fios que ora se rompem, ora se entrelaçam nas páginas de Ascendentes. O que o tecer aponta na história de minhas ancestrais? Por mais que eu utilize um sistema comunicativo diferente do Quéchua ou do que Vicuña apresenta em sua obra, acredito que o esgarçamento das tramas alude às perdas envoltas nas biografias dessas mulheres que encontrei, sejam aquelas do acervo público ou as minhas ascendentes.

\section{Considerações finais}

No contemporâneo, é visível o crescimento de investigações teóricas em torno do apagamento de mulheres em acervos históricos, assim como as proposições de mulheres artistas afrodescendentes e indígenas que questionam em seus projetos poéticos a partir de autobiografias, nas quais se apresentam possibilidades de reparação histórica diante da invisibilidade que essa população sofre ao longo de séculos nas narrativas oficiais.

Em Ascendentes, associo procedimentos de diferentes ordens. De um lado, trago aqueles que carregam saberes ancestrais, a exemplo dos chás medicinais, do bordado, da costura, que são atravessados de afetos compartilhados durante as rodas de conversas entre mulheres de geração a geração. Em contraponto, trago os de origem eurocêntrica, como o livro, a escrita e a fotografia, isto é, dispositivos que recorrentemente são utilizados pela historiografia para registro de pedagogias modernistas, na sua maioria de origem colonial. Quando estabeleço esses encontros, pretendo desestabilizar hierarquias entres esses conhecimentos. Assim, observo a formação de territórios híbridos possíveis em espaços íntimos do convívio doméstico que se interligam àqueles de caráter institucional. Nesses cruzamentos, surgem potências traduzidas em projetos poéticos.

Na procura dos fios que me formaram, escrevo por meio da ficção outras páginas acerca das minhas ancestrais. Para Luana Saturnino, o ato de contar a própria história por meio da poética artística não se dá pelo temor de perdê-la, mas em um processo de reinventar a si e ao mundo (TVARDOVSKAS, 2017). Acredito que os elementos biográficos que escolhi em torno da memória da minha família me auxiliam a reconstruir minha identidade étnica, a refazer os laços que me foram retirados, a atravessar afetos de diferentes ordens nas imagens das representadas selecionadas.

A cada fio que transponho para a trama do tecido, percebo que a memória sobre minhas parentes se manifesta em mim de outra forma, por meio de saberes manuais que entrelaço às representações de 
mulheres anonimizadas em arquivos públicos. Estabeleço uma conversa entre aquelas que sei chamar pelo nome, mas para quem não há imagens, e aquelas que foram fotografadas, mas sem identificações. Nesse diálogo, passado e presente se encontram; por sua vez, ausências se transformam em presenças, que antes eram nebulosas para mim.

Ao tecer nas páginas de um livro de artista os nomes das mulheres que trago em minha tessitura, reivindico uma existência que foi velada, violada, desamparada, esquecida, seja no lar, seja nas narrativas, seja nos documentos oficiais. Na linha visível evoco subjetividades invisíveis, pois os nomes sem os retratos correspondentes permitem que a leitora possa projetar a imagem de outras mulheres que fizeram parte de sua formação; nesse processo, outras vozes femininas se conectam por seus saberes, suas práticas e costumes.

\section{REFERÊNCIAS}

ADAMS, Telmo. Walsh, Catherine (Ed.). Pedagogías decoloniales: prácticas insurgentes de resistir, (re)existir y (re)vivir. Tomo I. Quito, Ecuador: Ediciones Abya-Yala, 2013. 553p. Práxis Educativa, Ponta Grossa, v.10, n.2, p.585-590, jul-dez. 2015.

BHABHA, Homi. O local da cultura. Trad. Ávila, M; Reis, E.; Gonçalves, G. Belo Horizonte: Editora UFMG, 1998.

BONFIM, Marcela. Abertura - mesa 1 | arte, crítica e a reinvenção dos direitos humanos. ABCA. 25 nov. 2020. Youtube (3h 14min 25s). Disponível em: $<$ https://www.youtube.com/watch?v=4LDPP4Uef6M>. Acesso em: 19 dez. 2020a.

Educação das relações étnico-raciais. LABCART - Laboratório de Geografia e Cartografia. 25 nov. 2020. Youtube (2h 7min 40s). Disponível em: < https://www.youtube.com/watch?v=rQ15_rz6IS8>. Acesso 19 dez. $2020 \mathrm{~b}$.

Acesso em: 20 jan. 2021.

Experiências. 2016. Disponível em: < https://www.amazonianegra.com.br/bio>.

BRASIL, Moara. Ser parda, ser mestiça, ser cabocla. O que eu sou? 2019. Disponível em: $<$ https://www.moarabrasil.com/single-post/ser-parda-ser-mesti\%C3\%A7a-ser-cabocla-o-que-eusou>. Acesso em: 18 out. 2020.

Sobre Moara Tupinambá. 2020

Disponível em:

<https://www.moarabrasil.com/moarabrasil-1>. Acesso em: 18 out. 2020.

CARVALHO, Diana. Artista registra a Amazônia em busca de novo olhar sobre o corpo negro. ECOA. 2020. Disponível em:<https://www.uol.com.br/ecoa/ultimas-noticias/2020/07/05/marcelabonfim-registra-a-amazonia-em-busca-de-desencarcerar-imagem-negra.htm>. Acesso em: $12 \mathrm{dez}$. 2020.

GONZALEZ, Lélia. Por um feminismo afro-latino-Americano. 1988. In Caderno de Formação Política do Círculo Palmarino n.1. Batalha de ideias. AfroLatinoAmérica, Brasil, p.12-20. 2011.

MARTINS, Esterffany. Pesquisa analisa ação anti-inflamatória do Crajiru. CONFAP - Conselho Nacional das Fundações Estaduais de Amparo à Pesquisa. 2017. Disponível em: $<$ https://confap.org.br/news/pesquisa-analisa-acao-anti-inflamatoria-do-crajiru/> . Acesso em: 20 jan. 2021.

NOCHLIN, Linda. Por que não houve grandes mulheres artistas? Trad. J. Vacaro. 2ed. São Paulo: Edições Aurora. 2016. Publicado originalmente pela ARTNews em 1971. Disponível em: $<\mathrm{http}$ ://www.edicoesaurora.com/ensaios/Ensaio6.pdf>. Acesso em: 06 set. 2020. 
OLIVEIRA, Márcia. Da palavra ao fio: as tessituras fluidas de Cecilia Vicuña. Revista Estudos Feministas, Florianópolis, v. 27, n. 1, p. 12-20, 2019.

REDE CHOQUE. Moara $\quad$ Brasil. $2020 . \quad$ Disponível em: $<$ https://www.choquecultural.com.br/pt/2020/05/26/rede-choque-apresenta-moara-brasil/>. Acesso em: 17 out. 2020.

SIMIONI, Ana Paula Cavalcanti. O corpo inacessível: as mulheres e o ensino artístico nas academias do século XIX. ArtCultura, Uberlândia, v. 9, n. 14, p. 83-97, jan.-jun. 2007.

TVARDOVSKAS, Luana Saturnino. Dramatização dos corpos: Arte contemporânea de mulheres no Brasil e na Argentina. Tese (Doutorado em História) Instituto de Filosofia e Ciências Humana, Universidade Estadual de Campinas, Campinas, 2013.

WALKER, Alice. Em busca dos jardins de nossas mães. 1972. Trad. LIMA, L. Publicado originalmente pela Search of Our Mothers' Gardens. In: MITCHELL, Angelyn (ed.). Within the Circle: An Anthology of African American Literary Criticism from the Harlem Renaissance to the Present. Durham and London: Duke University Press, 1994. Disponível em: $<$ https://docero.com.br/doc/5v0c1e>. Acesso em: 08 fev. 2021. 